\title{
Review of David Boonin, Beyond Roe: Why Abortion Should be Legal Even if the Fetus is a Person (Oxford University Press, 2019)
}

\author{
Kate Greasley ${ }^{1}$
}

Accepted: 29 April 2021 / Published online: 14 May 2021

(c) The Author(s) 2021

Should abortion be legal even if the human fetus is a person? "Person" is intended here in its philosophical sense, to mean a being possessed of equal moral standing and rights as you and me. Most importantly of all, a person is a being with the fundamental right to life. The question about what follows morally and legally when fetal personhood is presumed has occupied a sizeable part of abortion ethics for some time. Far and away the most influential reflection on that question was the philosopher Judith Thomson's "violinist analogy argument" in defence of abortion rights. ${ }^{1}$ There, Thomson argued that abortion is morally defensible even if it is true that the fetus is a rights-holding person. Her argument rested on a view of pregnancy as supererogatory, and, conversely, of abortion as the mere refusal to be a good Samaritan. Though it might be laudable to do so, no one is morally required to surrender her very body in order to keep another person alive for nine months, Thomson claimed. Ergo, even if fetuses are persons, women are not morally obliged to provide them with life-saving bodily aid by gestating them. They are morally permitted to refuse that bodily aid by means of abortion. They are permitted to choose not to be good Samaritans.

Thomson memorably posed this argument through an analogy in which you are kidnapped by a musical society and hooked up to an unconscious violinist whose kidneys are failing, and who needs to be plugged into your own kidneys for the next nine months in order to survive. After that, he will detach, and you can go your separate ways. As fate would have it, you are the only kidney match. Certainly, Thomson argued, it would be admirable for you to undertake this burden, but surely you do not have to. You are morally permitted to reach around your back and unplug yourself, knowing that the violinist will sadly die, she claimed, confident that the reader will share this judgement. Well, just so with pregnancy and abortion. I think of this

\footnotetext{
1 J. J. Thomson, 'A Defense of Abortion', Philosophy and Public Affairs 1:1 (Autumn 1971): 47-66.
}

Kate Greasley

kate.greasley@hertford.ox.ac.uk

$1 \quad$ Hertford College, University of Oxford, Oxford, UK 
as the "good Samaritan view" of abortion rights, since the kernel of the argument is that abortion is no more than the refusal to be a good Samaritan. The violinist analogy is aimed at making the moral permissibility of abortion difficult to refute, including if we presuppose fetal personhood. The violinist is certainly a person, and yet you may unplug. If one is permitted to unplug the violinist, knowing he will die, why is one not permitted to expel a fetus, knowing the same?

In Beyond Roe: Why Abortion Should be Legal Even if the Fetus is a Person (Oxford University Press, 2019), David Boonin presents an engaging restatement of this way of thinking about abortion, citing Thomson as its intellectual progenitor, and defending it against the more prominent objections to stack up in the years since Thomson's watershed intervention. In concert with Thomson, Boonin's main proposition is as the title makes plain: that the right to abortion is defensible in moral and, even more assuredly, in legal terms, even if the fetus is a person with the right to life. He writes in the preface:

My main goal in this book is to take the argument that Thomson pioneered in the moral context, adapt it to the legal context, and use it to argue that abortion should be legal even if the fetus is a person. (x)

Like Thomson, Boonin argues that abortion amounts to the refusal to provide an embryo or a fetus with life-sustaining aid that a pregnant person cannot be morally required to provide. Certainly, he claims, no one ought to be forced by law to provide that bodily support. Emulating Thomson's strategy, Boonin anchors his argument on an extended analogue. Unlike Thomson's hypothetical violinist, though, Boonin's is a real life case, which even found its way before a court. The case concerned an American man, Robert McFall, and his cousin, David Shimp. McFall had been diagnosed with aplastic anaemia, a life-threatening condition which threatened to soon take his life if he did not receive a bone marrow transplant. Initial tests indicated that McFall's cousin, David Shimp, was a potential match. But Shimp did not wish to donate his bone marrow in order to save McFall. In light of the refusal, McFall brought a legal action, effectively asking the court to force Shimp to donate. In McFall v. Shimp, that action was summarily dismissed by the presiding Judge Flaherty. ${ }^{2}$ 'Flaherty's basic point was simple:', writes Boonin, 'it would be wrong for the state to force Shimp to give McFall the bone marrow he needed. I'll bet you agree with Judge Flaherty about this.' (4).

In the first part of the book, Boonin draws out the main lesson of McFall v. Shimp, and seeks to show that if the reader agrees with that principle and the judge's decision in that case, she must, perforce, agree that abortion should remain legal even if the fetus is a person. The main lesson of the case, Boonin takes it, is that the right to life does not entail the right to the use of another person's body to stay alive. McFall definitely possessed the right to life. Still, he could not demand the use of Shimp's bone marrow in order to save his life. And certainly, we should think, the state ought not to force Shimp to make that bodily sacrifice. '[B]eing a person doesn't give you

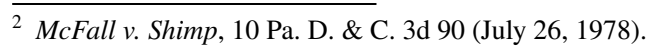


the right to use another person's bone marrow even if you need to use it.', Boonin writes (8).

Boonin sets out to establish that the same analysis applies to abortion on the assumption that the fetus is a person. If you believe that Shimp ought not to be forced to donate his bone marrow to McFall, then you should hold that the state ought not to force women to provide life-sustaining bodily aid to fetuses through gestation. But this it would do if it prohibited abortion, it is argued. He traces a number of different abortion scenarios, inviting the reader to presume in each that the fetus, like McFall, really is a person (amusingly, the fetuses are even given names, such as "Al" and "Bob" to help lock that presumption in place). Despite their various features, Boonin claims that all of these abortions are subsumed by the basic principle of McFall v. Shimp.

The second part of the book tackles a cache of objections to this initial argument, which largely proceed by asserting morally relevant disanalogies that may well hold between McFall v. Shimp and the abortion situation. Perhaps a pregnant woman is responsible for the situation that has now arisen, or could be said to have consensually risked pregnancy (both non-issues in McFall v. Shimp). Perhaps the precise way in which abortion causes fetal death raises distinct moral issues. Does it change things that a woman stands in a relation of biological parenthood to her fetus? And so on.

In the final part, Boonin argues that if you agree with the decision in McFall $v$. Shimp, you ought to hold not only that abortion prohibitions are illicit, but also that numerous restrictions on abortion access are indefensible as a matter of justice. Among the restrictions he addresses directly are mandatory counselling, waiting periods, and ultrasound requirements, all of which are in operation in some American states.

The importance of the entire 'good Samaritan' strain of abortion defence is patently apparent. On a typical reckoning, the philosophical personhood of the fetus is deeply inimical to abortion rights. This is because, while unwanted pregnancy no doubt imposes severe hardships on women, it is hard to make the case that homicide is a proportionate method of avoiding them in almost all cases. In morality and law, homicide is justified only in the direst of circumstances. Considering this, it would appear that everything in the abortion rights battle depends on the correct answer to the personhood question. Needless to say, though, the conditions for philosophical personhood are deeply (maybe even essentially) contested. If the permissibility of abortion can, somehow, be maintained in the face of prenatal personhood, we can spare ourselves grappling with the thorny question about the moral status of the fetus - and, indeed, about what confers personhood universally-on the path to defending abortion rights.

The good Samaritan argument has both moral and legal analogues. While Thomson was primarily concerned with establishing the moral permissibility of abortion, Boonin more emphatically sets out to make the case for the legal right to abort a fetus-person. ${ }^{3}$ On both scores, by grounding his version of the good Samaritan

\footnotetext{
${ }^{3}$ Although, one might think the claim about legal permissibility is implied in Thomson's version of the argument. It is passé to think that plenty of morally sub-optimal behaviour is not the law's proper con-
} 
argument on a real life case, Boonin's account has the relative virtue of being slightly closer to earth than Thomson's, where we might worry that the sheer bizarreness of the scenario makes it difficult to formulate reliable judgements. McFall v. Shimp actually happened, and Boonin is surely correct to suppose that its decision will be endorsed by most people. Relying on readers' judgements about that case is hence a solid departure point for further argument.

Admittedly, this advantage is diluted each time the original case is amended to something more outlandish so as to account for a possible morally relevant disanalogy with abortion. I am less sure, for instance, what the correct legal and moral response is where Shimp begins the scenario connected up to a 'bone marrow transferring machine' which is slowly extracting his bone marrow and transferring it to McFall, or where McFall turns out to be Shimp's offspring, than I am about the original case. This "changing-the-case" strategy-a staple of contemporary moral philosophy - is the argumentative method of choice for most of the book, and McFall v. Shimp undergoes multiple emendations to press the main thesis in the face of objections. For example, perhaps we are unsure that McFall v. Shimp applies equally to abortions in which the woman was in some way responsible in becoming pregnant, say, by engaging in consensual sex and forgoing contraceptive use. In that case, we should simply ask ourselves how things ought to stand in an amended case where Shimp is somehow responsible for the situation in which he is now connected up to McFall and already donating his bone marrow, the cessation of which will spell McFall's death-maybe he went tearing around McFall's hospital room in full knowledge that he might trip on the slippery floor and wind up stuck on the bone marrow transferring machine' (24). If we remain convinced that the law ought not to force Shimp to remain hooked up, his negligence notwithstanding, the disanalogy doesn't bite.

The doubt always lingers, though, that not every morally salient feature of the pregnancy situation can be adequately captured by a McFall v. Shimp Redux. And none, surely, can capture the combined force of everything that seems to matter in this domain. How would it change our moral evaluations of McFall and Shimp's case if people donating bone marrow to their cousins had been the method of bringing new humans into existence since time immemorial; if our private, social, and working lives were structured against the backdrop of this possibility, and even sat in expectation of it; if the act of donation had come to be considered (rightly or wrongly) as a pivotal aspect of the human experience, but one that also imposed disproportionate social and physical burdens upon the donors, an already disadvantaged class of citizens? It is unlikely that any tweaking of McFall v. Shimp can replicate all the realities which inform our moral response to the abortion problem, and, indeed, against the backdrop of which those moral sensibilities are developed and finessed to begin with. Perhaps the misgivings some have about the methodology which characterises Beyond Roe are not entirely without merit, then.

Footnote 3 (continued)

cern, and even less legitimate, we should therefore think, for the law to enforce positive assistance over and above what even morality requires us to do. 
This critical perspective having been duly noted, Boonin's constant appeal to intuitions about cases, changing the case in response to objections, and confidently escorting the reader from one conclusion to the next ("if the McFall v. Shimp principle applies to $\mathrm{X}$ abortion scenario, then it should also apply to $\mathrm{Y}$ abortion scenario"), makes for a readable and compelling discussion, well suited to the aims of the book and its intended wide readership. The arguments are elegantly simple and straightforward; the writing has a crisp, conversational style, and the book moves along at a good pace, with each concise chapter devoted to progressing the argument in one small step, or refuting an objection with little ceremony. Boonin clearly takes pains to make the book suitable for those unfamiliar with abortion ethics literature and the philosophically novice. As he states in the preface, the aim is for the book to be 'informal and accessible' (xii), and in this he succeeds, with a minor reservation about some parts in which the appeal to yet more "cases" feels like more of a hindrance than a help. The book does not presume any familiarity with either law or philosophy and is pleasingly free of disciplinary jargon.

Much of the book is in fact a précis of arguments more elaborately made by Boonin in his 2002 book A Defense of Abortion, repackaged and simplified for the general reader. ${ }^{4}$ In the earlier book, Boonin devotes an impressive chapter of over 200 pages to the systematic defence of Thomson's version of the good Samaritan argument. The chapter contains the most rigorous and robust defence of the view that abortion is morally permissible regardless of fetal personhood of which I am aware (my own copy is dog-eared and underlined throughout). Beyond Roe distils the essence of these arguments, and of the good Samaritan thesis, in a way that will be particularly useful for students or for those encountering philosophical abortion arguments for the first time. But it also has plenty to offer the more inducted, reminding us of the various pulse points in this corner of the discussion, and of where the exchanges will likely bottom out. The flip side of the book's punchy style is that there is little breathing space to expand arguments and attend to nuances. This can hardly be a complaint in the context, and it is only once or twice that the discussion suffers for it, by my lights. One possible example of where it does is around the discussions of sex-selective and fetal abnormality (or "disability") abortions-both tricky cases for one or other side of the abortion divide - where no reference is made to some salient moral and legal considerations beyond the so-called fetal-maternal conflict.

The timing of Beyond Roe, at what appears to be a critical juncture for the abortion right in the United States, cannot be a coincidence. After recent personnel shifts on the US Supreme Court, Roe v. Wade, along with its determination against fetal personhood, is seemingly more precarious now than it has been in decades. The landmark decision in Roe v. Wade is familiar to most people as the case in which women's constitutional right to terminate their pregnancies was first recognised, ${ }^{5}$ Fewer people are aware that Justice Blackmun premised the court's majority judgment on the denial of the fetus's personhood under the Constitution. Women's right

\footnotetext{
${ }^{4}$ D. Boonin, A Defense of Abortion (Cambridge University Press, 2002).

5 Roe v. Wade 410 U.S. 113 (1973).
} 
to privacy did afford them the qualified right to abortion, it was held, but could not have done if the fetus were a recognised person under the law, and entitled to the constitutional protections that triggered. Had the Constitution recognised prenatal persons, the abortion right would fail, Justice Blackmun reasoned, 'for the fetus's right to life would then be guaranteed specifically by the amendment'. ${ }^{6}$

In so holding, Roe embraced the orthodox view of abortion ethics set out above: that the right to abortion is incompatible with the personhood of the fetus. As the antithesis to this view, the good Samaritan argument has increased legal and political relevance in any climate where the ascription of legal personhood to the fetus is a real possibility. Boonin articulates a basis for the abortion right that is impervious to a finding of fetal personhood. It is in this sense that his argument goes "beyond Roe". By pre-empting a legal turn affirming the constitutional personhood of the fetus, and illustrating how the abortion right could be defended consistently with it, the book is a welcome example of what philosophical legal advocacy can look like.

Garnering the reader's sympathy for the main principle about the limits of positive bodily duties (the 'lesson' of McFall v. Shimp) is always going to be the easier part for the good Samaritan argument. To reiterate, the principle is that the right to life does not entail the right to use another person's body in order to live. This is because the right to life does not ground a correlative duty on others to keep someone alive by such means, and no one should be forced to undertake burdens they are not morally required to bear. (This is not to deny that there are morally egregious refusals to save: Thomson herself admits that someone who refused to sustain the violinist for merely one hour, when that is all it would take to save him, would be 'morally indecent'. ')

Few would probably object thus far. The harder sell is always to show that the principle applies to pregnancy and abortion the same way it applies to McFall $v$. Shimp, and that morally relevant disanalogies do not knock it out of the arena. Boonin documents some of the main objections along these lines and provides a good demonstration of how someone defending the good Samaritan view could defuse them, the persuasiveness of which it is for the reader to evaluate. A cluster of those objections raise the possibility that the positive obligations a woman might owe to her fetus do not match up with McFall v. Shimp. This is the tenor of the responsibility objection (pp. 69-83), which points out that pregnant women can be responsible for the fetus's situation of need in a way that is not true of Shimp vis-àvis $\mathrm{McF}$ all. And it is trite that greater responsibility grounds greater obligations.

But a more fundamental objection targets the very framing of the abortion issue in terms of whether woman has a positive duty to gestate a fetus. On the good Samaritan view, the ethical question is whether one person's positive obligations of assistance extend to proffering the use of her body for someone else's survival, the answer being that, certainly in abortion, they do not. Yet an obvious objection is that abortion is not a positive obligations problem to begin with, but rather a problem about when one is permitted to breach the negative duty not to kill. We may be

\footnotetext{
6 ibid 157.

7 Thomson, 'A Defense of Abortion', 59.
} 
satisfied that Shimp merely allowed McFall to die when he refused to donate his bone marrow. In that case, the immanent moral issue is only whether Shimp ought to have saved McFall or not. But it seems that when "Alice" aborts "Al", she (or her doctors) is positively killing Al. If so, the good Samaritan analysis is in some trouble. In both law and morality, the circumstances in which we are permitted to kill outright are far stricter than those in which we are permitted to refuse to save. It doesn't follow, then, from the fact that Shimp has no duty to rescue McFall that Alice is permitted to kill Al to spare herself similar (or, even, worse) burdens. This is the familiar "killing v letting die" objection to Thomson's original defence of abortion.

As Boonin notes, it looks as though only some types of abortions, such as those which expel a pre-viable fetus from the uterus without attacking it directly, are readily analysable in terms of refusing to save, on a par with Shimp's omission (109). Other abortion methods better resemble direct killing which, presuming fetal personhood, would make the issue one of homicide. Homicide may yet be justified, of course, but its road to justification is not easy.

Boonin's general strategy against the killing v letting die objection, only really glimpsed at here, is to press the implications of special constraints on positive killing where they most rub. For example, most people, Boonin says, will likely think it matters not whether an abortion is carried out by dilation and curettage, a method that directly kills the fetus in the process of extraction, or instead by hysterotomy, where a pre-viable fetus is removed from the uterine environment it needs to survive, given that the result, fetal death, is the same. Added pressure can be applied using another amended version of McFall v. Shimp. Let us change the case again, Boonin suggests, to have it that Shimp is already unhappily hooked up to the bonemarrow transferring machine, only this time it is not enough to free Shimp to simply sever the connection; to free Shimp, a doctor must kill McFall outright, albeit painlessly in his sleep (114). If you think the doctor ought to be able to do this, Boonin argues, then you can have no objection to a mode of abortion that directly kills $\mathrm{Al}$ the fetus. More than this, though, you should have no objection to the direct killing of McFall in the amended case:

Since McFall has no right to the life support he's receiving and would be dead if he weren't receiving it, you may well think Shimp is entitled to withdraw that support even if doing so involves taking McFall's life. Since McFall has no right to remain alive at Shimp's expense after all, doing so would not make McFall any worse off than he has the right to be.' (115-116)

But that cannot be a full and correct statement of a condition for permissible killing. It is not the case that one is permitted to kill just whenever the killing is done so as to liberate oneself from a burden one would not have been duty-bound to offer, or when the killing will not leave the victim any worse off than she has a right to be, vis-à-vis the killer. Let us assume I have no duty to save you from rough sleeping 
and death from exposure by handing you over the contents of my bank account. ${ }^{8}$ Does that mean I am permitted to kill you so as to prevent you from commandeering those funds by force? Unlike Boonin, I am less sure we can read directly off a person's rights to life-saving assistance the extent of her rights against being killed so as to spare someone that that assistance.

Anyone unimpressed by the idea of an intrinsic moral difference between killing and letting die will no doubt deny that Alice cannot abort Al by dilation and curettage if she can abort by hysterotomy. This may seem all the more the case when the outcome for the fetus is the same either way but where the latter "letting die" method is more physically costly to Alice. ${ }^{9}$ Yet those who embrace strict deontological constraints on positive killing know that it will sometimes prove costly on other metrics of goodness. This line of reply only seems to beg the question against the killing/letting die distinction wholesale. We know that the difference is of moral consequence: my moral duty to save people from starvation through charitable donations is nothing like my moral duty not to poison those same people. If the distinction matters morally and intrinsically, why does it not matter here? That is the challenge.

If the morality and legality of abortion cannot, ultimately, fall to be treated as a positive obligations problem, we may find ourselves directed back to the more fundamental matter of fetal moral status. This brings me around, finally, to what motivates the good Samaritan thesis and the entire strain of personhood-bypassing abortion argument. 'The traditional approach of arguing about fetal personhood doesn't appear to be working too well', Boonin writes toward the beginning of the book (6). By what standards, though? One could well say the same thing about the good Samaritan view, given how little favour it has found among those who really do avow prenatal personhood. ${ }^{10}$ The personhood question is intractable insofar as it has not yielded universal agreement about the fetus. Is this different, in this respect, from any other core moral dispute that bears on our legal rights? (Consider: there is not yet universal agreement that the institution of property rights is anything other than state-sanctioned theft.) It is a virtue of the good Samaritan defence of abortion, Boonin says, that it is not susceptible to sorites-type anxieties about where the exact threshold of personhood lies, or about how we are to morally distinguish abortion from infanticide, although he acknowledges that personhood-denying defences of abortion do field answers to these quandaries. And indeed they do. Is it much harder to persuade someone of those answers than to persuade her that abortion is tantamount to the morally permissible refusal to proffer life-saving bodily aid?

Asking what follows about abortion rights if the fetus is indeed a person is without doubt a revealing and worthwhile exercise. Even so, our imaginations tend to buckle under the strain of that presumption at certain points-hence, perhaps, the need to assist by giving the fetuses names ("Al", "Bob", "Daniel"), and help animate them as persons. What moral duties do we owe to abstract "persons" that are

\footnotetext{
${ }^{8}$ I am by no means convinced that I would have no such duty.

9 Boonin discusses this issue at 117-119.

${ }^{10}$ I have yet to come across someone who subscribes to prenatal personhood and yet regards abortion as morally and legally defensible in broadly good Samaritan terms.
} 
nothing like persons as we ordinarily conceive of them: without their separateness, their embedment in social life, their transparent vulnerability and emotion? This is perhaps not a question our moral sensibilities have been honed to answer. To object that it chafes too much to speak of the fetuses "Al" and "Bob" invites the obvious retort that one has simply stopped playing the intellectual game. Still, finding the game unplayable on these terms can be telling in itself.

A minor theme of Beyond Roe is the explanatory power of the good Samaritan defence of abortion rights over personhood-denying accounts. ${ }^{11}$ But the personhood-denying defence has explanatory heft of its own. I end by noting just one way in which this is so. Like Thomson, Boonin accepts that the defence of abortion he outlines in Beyond Roe is more narrowly what has been called a defence of extraction. Boonin does not here assert a specific right to kill a fetus-person, only the right to end gestational support knowing this will spell fetal death (47-48). This poses clear problems for post-viability abortions, at which point the fetus could alternatively be extracted alive, still ending the woman's bodily support. If a woman can expel a fetus alive, the good Samaritan argument does not hold that she is entitled to insist on fetal death, it seems.

Boonin regards this problem as being of limited practical import given how few abortions occur past the point of fetal viability. But recent developments in artificial womb technology threaten to force the issue of whether it is abortion or extraction (or both) that is ethically and legally licit. Whilst still exploratory, these developments hint at new possibilities for early fetal, and even embryonic, survival outside of the uterine environment. Suppose that an unwanted ten-week embryo could be removed from a pregnant woman's womb and artificially gestated though to maturity. Where does this leave the abortion right on the good Samaritan defence? If we think the woman still ought to be able to control her procreative destiny by intentionally ending the life of that embryo, it is not the good Samaritan argument which will tell us this is so. What this action amounts to in moral terms, and how it should be treated under the law, will surely then depend on the intrinsic moral status of that embryo. Is it a creature whose life we are permitted to end so as to secure the allround wellbeing of a more developed human being, or is it not?

With possibilities such as ectogenesis on the horizon, the question about the moral status of the fetus cannot be easily batted aside (and it would be remiss not to mention here that Boonin has elsewhere advanced developed views about moral status before birth ${ }^{12}$ ). Changing legal and bio-technological landscapes will likely continue to press on both core questions in abortion ethics: is the fetus a rights-holding person, and, if so, what is the normative relevance of that? What Boonin presents here is a perspicuous and engaging treatment of the second issue.

\footnotetext{
${ }^{11}$ For instance, he suggests, it explains why there is in fact no inconsistency in defending abortion rights while maintaining that fetuses can be adjudged victims of crimes, through, inter alia, 'feticide' laws. At a glance, feticide laws seem to 'stand or fall together' with the prohibition of abortion, all depending on one's view of prenatal personhood. But the good Samaritan thesis explains why the abortion right could sit alongside feticide laws. The fact that Shimp should not be forced to let McFall use his bone marrow does not mean that McFall should not be treated as a victim if an armed robber comes along and kills him (55).

${ }^{12}$ See: A Defense of Abortion (above).
} 
Open Access This article is licensed under a Creative Commons Attribution 4.0 International License, which permits use, sharing, adaptation, distribution and reproduction in any medium or format, as long as you give appropriate credit to the original author(s) and the source, provide a link to the Creative Commons licence, and indicate if changes were made. The images or other third party material in this article are included in the article's Creative Commons licence, unless indicated otherwise in a credit line to the material. If material is not included in the article's Creative Commons licence and your intended use is not permitted by statutory regulation or exceeds the permitted use, you will need to obtain permission directly from the copyright holder. To view a copy of this licence, visit http://creativecommons.org/ licenses/by/4.0/.

\section{References}

Boonin, D (2002) A Defense of Abortion (Cambridge University Press)

Boonin, D (2019) Beyond Roe: Why Abortion Should be Legal Even if the Fetus is a Person (Oxford University Press)

J. J. Thomson, ‘A Defense of Abortion', Philosophy and Public Affairs 1:1 (Autumn 1971): 47-66.

Publisher's Note Springer Nature remains neutral with regard to jurisdictional claims in published maps and institutional affiliations. 